\title{
El circuito algodonero-textil en Formosa, Argentina 2003-2015
}

\author{
Sergio Omar Sapkus* \\ Ernesto Fabián Giuliano**
}

Fecha de recepción: 28 de diciembre de 2019

Fecha de aceptación: 15 de abril de 2020

Resumen: En el presente trabajo se analiza la política pública subnacional en Argentina. Concretamente, se estudian las actividades de las instituciones de Gobierno en Formosa, provincia de la periferia rezagada del país, diferenciada por su escaso dinamismo económico e históricamente marginalizada en la configuración socioespacial nacional. Se pretende mostrar que pese al giro "posneoliberal" del Estado argentino en el período considerado, las políticas regionales/locales implementadas en este nivel distrital siguen un curso neoliberalizador. Empíricamente, ponemos el foco en la intervención sectorial/ territorial alrededor de algunos eslabones de la cadena algodonera-textil afincada en la provincia entre 2003 y 2015. Concluimos que, amoldada a las ideas de la nueva ortodoxia regionalista, la política pública comarcana se orienta a imponer la disciplina de mercado por vías estatales, manteniendo subordinadas las agendas políticas y sociales a la prioridad de mantener la confianza de los inversores y el buen clima de negocios, la competitividad territorial y un mercado de trabajo flexibilizado.

Palabras clave: Estado, Argentina, neoliberalismo, nuevo regionalismo, flexibilidad, algodón.

Clasificación JEL: R11, R58, Q16, I38, J46

Cómo citar este artículo/ To reference this article / Comment citer cet article / Para citar este artigo: Sapkus, S., \& Giuliano, E. (2020). El circuito algodonero-textil en Formosa, Argentina 2003-2015. Apuntes Del Cenes, 39(70).Págs. 209 - 232. https://doi.org/10.19053/01203053.v39.n70.2020.10483

\footnotetext{
* Licenciado en Ciencias Antropológicas- orientación sociocultural y Magister en Antropología Social. Profesor de la Universidad Nacional de Formosa, Argentina. Correo electrónico: sergiosapkus@gmail.com

** Universidad Nacional de Formosa. Argentina. Correo electrónico: giulianoernesto02@gmail.com (iD https://orcid. org/0000-0002-9699-8148
} 


\title{
The Cotton-Textile Circuit in Formosa, Argentina 2003-2015
}

\begin{abstract}
This paper analyzes the subnational public policy in Argentina. Specifically, the state intervention in Formosa is studied, a province of the lagging periphery, differentiated by its low economic dynamism and historically marginalized in the national socio-spatial configuration. It is intended to show that, despite the "postneoliberal" turn of the Argentinian state in the period considered, the local/regional policies implemented in Formosa follow a neoliberalizing course. We take as a specific case study the policy followed around a sector/territorial intervention on some links of the cotton-textile chain based in the province between 2003 and 2015. We concluded that, based on the ideas of New Regional Orthodoxy, the regional public policy is oriented to impose market discipline by state channels, keeping subordinated political and social agendas to the priority of maintaining investor confidence and the good climate business, territorial competitiveness and flexible labor market.
\end{abstract}

Keywords: state; Argentina; neoliberalism; new regionalism; flexibility; cotton. 


\section{INTRODUCCIÓN}

La superación de los problemas estructurales de pobreza, marginalidad y desigualdad continúa siendo objeto de debate académico y político en Argentina y América Latina. Esta querella adquirió nuevas aristas a partir del giro "progresista" tomado por los gobiernos de varios países latinoamericanos a comienzos de este siglo, cuando comenzaron a recalibrar la relación Estado-economía, alejándose -en grados diversos- del neoliberalismo extremo, y a ofrecer una provisión social más extensa y generosa. Dimensionar la profundidad de este alejamiento del canon neoliberal $\mathrm{y}$, en añadidura, el carácter real de las políticas llevadas adelante por estos gobiernos y sus consecuencias para el bienestar de sus poblaciones, se convirtió entonces en un tópico decisivo de este debate.

En Argentina, que formó parte de esta mudanza política, se perfilaron dos posturas. Por un lado, un conjunto de autores plantea que el giro político engendró un "modelo" socioeconómico nítidamente dispar y alternativo al previo, al que bautizaron "nuevo proyecto de desarrollo con inclusión" (Madoery, 2011; Panigo \& Chena, 2011). Por el otro, un grupo diferente enfatiza los rasgos poco encomiables, tanto en términos de continuidad de las disparidades territoriales como en la reproducción de la precariedad de la vida de los grupos subalternos que, según ellos, siguen siendo los datos esenciales de la economía argentina. Enfatizan, en tal sentido, las continuidades más profundas entre ambos momentos (Salvia \& Gutiérrez-Ageitos, 2013; Fernández, 2016).

A partir de esta controversia, y como un aporte a la clarificación de algunas de sus dimensiones, pretendemos en este trabajo ponderar determinados aspectos de la política pública argentina en regiones rezagadas a partir de 2003. Específicamente nos concentramos en lo acontecido en una provincia del extremo norte del país: Formosa, ejemplo paradigmático de territorios estancados económicamente e históricamente marginalizados en la configuración socioespacial argentina. 
Formosa integra el grupo de unidades subnacionales de la denominada "periferia rezagada" (Cao \& Vaca, 2006) de la Argentina. Este grupo se caracteriza por tener "un marcado retraso productivo y empresarial", de modo tal que constituye el área de "menor desarrollo relativo del país", presentando niveles muy bajos de desarrollo humano (Cao \& Vaca, 2006, p. 109). Formosa, específicamente, es la provincia que menos aporta al producto nacional -en 2005 su PBG significaba el $0.5 \%$ del PBI de Argentina-. Su estructura económica se asienta predominantemente en el sector terciario. El grueso de las actividades en este sector corresponde al sector informal, mientras que en el sector formal, tanto en empleo como en producto, predominan las actividades de la administración pública. El sector manufacturero tiene un aporte secundario, a la vez que el sector primario, escasamente modernizado, sigue siendo una actividad de relieve para la economía provincial. Para resumir, la formación social de la provincia de Formosa presenta de forma acentuada los rasgos clásicos del "subdesarrollo", y configura en tal sentido un caso palmario de "periferia extrema" dentro de la formación social argentina.

En este espacio ostensiblemente marginalizado, y ya desde los años noventa, las elites estatales han desplegado diferentes intervenciones enmarcadas en lo que de manera genérica podemos llamar políticas de "desarrollo local" o regional. Estas, por añadidura, tienen como orientación, tácita o explícita, lo que se ha denominado nueva ortodoxia regional (NOR) (Fernández \& Cardozo, 2012), un conjunto de ideas y políticas elaboradas en los países del centro, consideradas como la mejor manera de promover el crecimiento económico y la cohesión social en el mundo globalizado. Si bien las consideraciones sobre el desarrollo local han adquirido, al calor del giro ideológico contra el neoliberalismo que venimos comentando, nuevas tonalidades "neodesarrollistas", su sello neoliberalizador es, entendemos, insoslayable. En tal sentido, consideramos que las acciones acometidas por la elite estatal que comanda el Estado provincial, pueden ser entendidas como una versión local del proceso de neoliberalización y de las prescripciones de la NOR.

Respondiendo a esta idea, abordamos aquí las intervenciones de política pública emprendidas por el Estado provincial -en articulación con otros niveles estatales- en el subsector algodonero-textil durante 2003 y 2015.

El material empírico que presentamos para fundamentar nuestro postulado fue construido a partir de diversas fuentes de información, fundamentalmente de carácter cualitativo. Así, consultamos documentos y estadísticas de los organismos oficiales (provinciales y nacionales) y realizamos entrevistas a informantes calificados involucrados en diferentes esferas de la burocracia provincial, así como también a actores implicados en el quehacer agrícola y en 
actividades del sector informal urbano. Además, consultamos diversos medios periodísticos de la ciudad de Formosa, capital de la provincia (escritos y audiovisuales) $^{1}$

En lo que sigue, el trabajo se ordena en dos acápites. En el primer apartado, discutimos el surgimiento y la orientación general de la NOR y su implantación en la provincia de Formosa. En la segunda parte nos adentramos en el análisis de las intervenciones estatales en el Complejo Algodonero Formoseño. En último término, presentamos las conclusiones.

\section{SURGIMIENTO Y ORIENTACIÓN GENERAL DE LA NUEVA OR- TODOXIA REGIONAL Y SU IM- PLANTACIÓN EN LA PROVINCIA DE FORMOSA}

Hacia los setenta del siglo pasado se agotó la era "fordista" del capitalismo. Desde entonces un proceso multidimensional de cambio social recorre el planeta, sacudiendo la organización económica y las formaciones políticas, y junto a ello también los arreglos sociales y los repertorios culturales. Habitan el núcleo de estas transformaciones económicas la internacionalización del comercio, las inversiones y las finanzas, concurrentemente con la especialización "flexible" y la descentralización de la producción. En conjunto, tales mutaciones afectaron poderosamente las formas de regulación económica por parte del Estado y redefinieron el "acoplamiento" estructural de lo económico y lo político. Particularmente, minaron la economía nacional como objeto de gestión estatal. Los Estados nacionales, así, se convirtieron en dominios fracturados de autoridad política, asediados por las presiones sobre sus funciones, jurisdicciones y capacidades.

El debilitamiento del ámbito nacional como esfera prioritaria de la organización económica es el resultado de un triple movimiento (Jessop, 2008): la transferencia de algunas de las capacidades y funciones del Estado nacional a cuerpos internacionales; la delegación de otras a niveles locales dentro del Estado nacional; y la usurpación de otras aún por parte de redes emergentes horizontales (locales y regionales) que pasan de largo los Estados centrales y conectan las localidades y las regiones en naciones diversas. El desmantelamiento del capitalismo "organizado" de posguerra, centrado en el Estado nacional y su rol marcadamente intervencionista, desató, de la mano de la reestructuración económica, una reconfiguración de las escalas políticas, ganando prominencia los niveles subnacionales y globales.

Acompañando estas transformaciones de la articulación política-economía en el núcleo del sistema capitalista, tanto en la literatura académica como en los

1 La investigación está enmarcada en el Proyecto 54/FH 131 Agro y sociedad en la provincia de Formosa. La ruralidad provinciana en años de posneoliberalismo, financiado por la Secretaría de Ciencia y Tecnología de la Universidad Nacional de Formosa (Argentina). 
discursos técnicos y de los formuladores de política, comienza a considerarse la escala regional como la unidad fundamental de la vida social del capitalismo contemporáneo y núcleo central de coordinación de las formas más avanzadas de la vida económica. En consecuencia, comienza a concebírsela como un nivel privilegiado en el diseño de políticas. Un estímulo particular al sazonado de la mirada regionalista fue la percepción de que entre 1970 y 1980 algunas regiones en las economías capitalistas desarrolladas crecían más rápido que los núcleos industriales establecidos dentro de esos mismos países. Se observaba también que en estas nuevas comarcas dinámicas, a las que se comenzó a llamar "distritos industriales", prevalecían pequeñas empresas, empapadas de un vago espíritu local emprendedorista. Esto contradecía las teorías y políticas dominantes en ese momento basadas en grandes proyectos de infraestructura, grandes inversiones industriales y una fuerte guía/asistencia del Estado. Muy pronto tales regiones, sus pequeñas firmas y su estructura social se convirtieron en los símbolos del éxito del capitalismo a pequeña escala, "desde abajo", con su carácter altamente competitivo y empresarial/ emprendedorista. Pasaron a ser así un modelo para ser emulado.

Esta lectura se volcó a las políticas de los Estados europeos en la década de los noventa, convirtiéndose en la piedra an- gular del llamado nuevo regionalismo. Muy rápidamente sus abogados la transformaron en ortodoxia, amalgamando procesos y áreas en una sola categoría, promoviéndola como el prototipo de una nueva era global de acumulación y crecimiento (Amin \& Robins, 1990; Hadjimichalis, 2011). Adquiere así la NOR un contorno definido (Fernández \& Cardozo, 2012), que seguidamente comienza a ser promocionada también como una oportunidad para la regeneración de las economías locales y regionales de los países del Sur Global. $\mathrm{Su}$ postulado de base, en términos de ejercicio estatal, es que la única manera de lograr el crecimiento económico y la armonía social de los espacios subnacionales reside en conectarlos, vía fomento de la competitividad, a los circuitos supranacionales (globales) de actividad económica.

A todo esto, la etapa superior del neoliberalismo se imponía rigurosamente en América Latina. En Argentina, concretamente, el lanzamiento del llamado Plan de Convertibilidad en 1991, amoldado a los lineamientos del Consenso de Washington, reimponía brutalmente la tiranía del mercado ${ }^{2}$. Como paquete económico de "ajuste estructural" sustentado ideológicamente con la economía neoclásica, este programa comprendía procesos de privatizaciones, de desregulación, de la liberalización y de descentralización administrativa.

2 La Ley de Convertibilidad se refiere al plan económico aprobado con la Ley n. 23.298 en marzo de 1991, que estableció un tipo de cambio fijo con caja de conversión a la tasa de un peso por un dólar. 
Argentina se destacó particularmente por la implementación más fervorosa de este modelo de apertura.

La consolidación del neoliberalismo redefinió profundamente la relación entre Estado y mercado en Argentina, dándole cierre definitivo al modelo de desarrollo vigente desde la década de 1930, y reestructurando regresivamente las relaciones entre capital y trabajo. Realmente, la ofensiva neoliberal de los noventa desguazó el Estado populista-interventor asociado al modelo de desarrollo basado en la industrialización por sustitución de importaciones en una economía semicerrada, con redistribución progresiva del ingreso y con políticas activas de intervención estatal en la economía. Emergió en su reemplazo un modelo de desarrollo basado en la producción y exportación de productos básicos de escaso valor agregado, con un mercado interno reducido, acoplado a una forma de Estado neoliberal o neoconservadora. Como parte de esta mudanza, la modalidad periférica y sui generis del Estado de bienestar adoptado por el Estado argentino desde los 1940 también fue socavada y reemplazada, para atender las profundas consecuencias sociales de todo el proceso de ajuste, por formas cercanas al "trabajismo"3.
El Régimen de Convertibilidad tuvo un impacto devastador mayúsculo en los espacios subnacionales periféricos y empobrecidos como Formosa. Las políticas de desregulación y privatización de entes públicos y de apertura comercial indiscriminada desarmaron la armadura que permitía la reproducción de las pequeñas y medianas explotaciones agropecuarias, sostén de la economía provincial en la etapa "desarrollista" (ver Manzanal, 2000; Cetrángolo \& Gatto, 2002). De esta suerte, la provincia sufrió uno de los procesos más severos de reducción de las actividades productivas (Cetrángolo \& Gatto, 2002). Sumado a eso, la transferencia de funciones y decisiones concentradas hasta ese entonces en el Estado nacional hacia el Estado provincial, sin ser acompañada por los recursos adecuados, potenció las consecuencias deletéreas sobre las condiciones socioeconómicas de la jurisdicción.

Las prescripciones de la NOR aparecen precisamente en este momento álgido de la terapia de choque neoliberal para alentar la regeneración de las "economías regionales" argentinas y como marco orientador de la política pública del endeble Estado provincial formoseño. En esta coyuntura lo hace fundamentalmente a través de las intervenciones diseñadas para expandir el dominio del capital en las comarcas más aisladas del territorio provincial: el ex-

3 Jessop sintetiza la idea clave del "trabajismo" ("workfarism") diciendo que se trata de "una reorientación general de la política social desde la visión redistributiva basad en la extensión de derechos sociales en un Estado nacional hacia un tipo de enfoque más productivista y dirigido al ahorro de costes en una economía abierta" $(2008$, p. 316). 
tremo oeste. Por un lado, con el proyecto de colonización para el centro-oeste, un ambicioso plan de infraestructura y diseño de legislación, emprendido por el Estado provincial, orientado a atraer a la inversión extranjera ligada a los agronegocios. A este emprendimiento, y adaptando la noción de "anclaje espacio-temporal" de David Harvey (2004), Giuliano (2015) lo califica Anclaje Espacial del Centro-Oeste. Por otro lado, con el Bosque Modelo Formoseño, una asociación voluntaria de personas interesadas en el "desarrollo forestal sustentable local" creada a fines de la década del noventa bajo el patrocinio del Estado nacional y anclada en la lógica de la descentralización y las nuevas formas de gobernanza neoliberal de partenariado público-privado (ver Tabla 1).

Gestionando entusiastamente este proceso neoliberalizador a escala subnacional, la elite administradora del Estado provincial pergeña en esa década un discurso performativo sobre el "modelo formoseño" que, con el tiempo confluye y se retroalimenta con los insumos importados de la $\mathrm{NOR}^{4}$. El mentado modelo, basado en la postulación de una "identidad" sustentada en una cultura pública homogénea "formoseña" -que aseguraría una disposición hacia la confianza mutua entre otros rasgos de comportamiento-, se plantea como una configuración, alentada por el Estado provincial, de un "ambiente de negocios" en donde confluyan actores diversos que puedan movilizar endógenamente los recursos existentes con vistas a aprovechar las oportunidades del mercado global. De este modo se iban sentando las bases para el despliegue pleno de intervenciones de "desarrollo local y regional", en el marco del "regionalismo empresarial", en la década siguiente.

La caída catastrófica del alto neoliberalismo en Argentina a fines de 2001, en medio de una profunda crisis política, económica y social, da una vuelta de tuerca a este curso neoliberalizador. La salida de este crac tuvo como punto de arranque el abandono abrupto de la convertibilidad a través de una megadevaluación y, desde entonces, un viraje hacia una revalorización de la intervención estatal para orientar el desarrollo económico capitalista, moderando el brutal disciplinamiento del mercado de los noventa ${ }^{5}$. Asimismo, también comienza a delinearse un rol más activo del Estado como agente de redistribución en vistas a mitigar las deletéreas consecuencias sociales de la trayectoria económica del país. Esta orientación se profundiza en 2003 con la asunción del presidente Néstor Kirchner. Queda

$4 \quad$ Dicho discurso se esgrime ya en los preámbulos de las reformas constitucionales de los años 1991 y 2003 , que hacen referencia a la voluntad de “(...) plasmar el modelo formoseño para un proyecto provincial (...)". Cabe aclarar que en la provincia de Formosa gobierna ininterrumpidamente el mismo partido político desde el año 1983 (cuando regresa la democracia al país). Desde 1995, el cargo de gobernador es ejercido por la misma persona. 5 El 7 de enero de 2002 se promulgó la Ley n. ${ }^{\circ} 25.561$ (de Emergencia Pública y de Reforma del Régimen Cambiario)
que dispuso los cuatro pilares de salida de la crisis: la devaluación de la moneda argentina, la licuación de deudas mediante su pesificación, la instauración de retenciones a la exportación y el congelamiento de las tarifas de servicios públicos (que se habían privatizado la década anterior). 
delineado así, y hasta 2015, un "modelo económico" que, dentro de las experiencias "posneoliberales" de tonalidad progresista que proliferaron en Sudamérica -mencionadas al inicio de este artículo- ha sido calificado desde distintas vertientes de "neodesarrollista" (Katz, 2013; Fernández, 2016; Féliz, 2019).

No obstante, esta mudanza no alcanzó el corazón de las transformaciones de los noventa, ya que "la salida de la crisis se dio manteniendo la mayoría de las reformas neoliberales, con un aparato productivo modernizado, con condiciones flexibilizadas de contratación y consumo de fuerza de trabajo, apertura comercial y eliminación de regulaciones estatales sobre la actividad privada" (Salvia, 2019, pp. 60, 68). Por ello, en definitiva, la experiencia "neodesarrollista" argentina se recorta como un "momento fenómenico" (Pinassi \& Adoue, 2019, p. 13) interno de un proceso neoliberalizador de más largo aliento, como una "reacción" -aunque no antagónica- (Fernández \& Cardozo, 2012, p. 16) ante los efectos disolventes del momento anterior del mismo.

Así, si bien a partir del 2002-2003 se puede observar "un nuevo protagonismo del Estado Nacional en la economía" y, específicamente, en "la dinámica económica y territorial" (Adriani, 2016), esto no significa que se haya desdibujado sustancialmente la lógica neoliberali- zadora. Ariel García, desde una postura amigable hacia la gestión "neodesarrollista", apunta en este sentido que si bien hubo un "avance elocuente" en los instrumentos de política pública de los que dispuso el Estado nacional en relación con la problemática regional, "la tradicional función facilitadora del Estado, que actúa como jardinero, no se ha modificado aún" (2016, p. 190). Fernández y Comba (2017), desde una postura más crítica, rematan de modo tajante: "las políticas neoliberales (...) continuaron casi sin alteraciones (o con pequeños ajustes incrementales) en un escenario de (re) industrialización sustitutiva de importaciones o neodesarrollista" (p. 378).

En este marco, se destacan dos líneas de intervención estatal sobre la cuestión regional en esta etapa: el Plan Estratégico Territorial (PET) y los Planes Estratégicos de Desarrollo Local (PEDL). El PET nació en 2004 coordinado, a través de la Subsecretaría de Planificación Territorial de la Inversión Pública, por el Ministerio de Planificación Federal Inversión y Servicios Públicos ${ }^{6}$. Según los documentos oficiales, el PET se propone construir un marco de referencia que ayude a orientar las políticas públicas, con la participación asociada de los niveles subnacionales del Estado y la "sociedad civil". La orientación más general habla de construir un "plan general de desarrollo equilibrado y

6 Desde el año 2015 la subsecretaría funciona en el ámbito del Ministerio del Interior, Obras Públicas y Vivienda. (Argentina.gob.ar, s.f.) 
equitativo" de los territorios provinciales, mediante en la intervención en la composición territorial del país, en el rescate de capacidades "locales", la mejora del desarrollo de redes urbanas, incrementar y racionalizar las dotaciones de infraestructura, y el trabajo general sobre las zonas más rezagadas poniendo en valor sus propios recursos humanos y naturales. Vinculada a esta manera de entender "el desarrollo territorial de nivel provincial y local", comienzan a desarrollarse paralelamente los PEDL. En este caso, es el Consejo Federal de Inversiones (CFI), a través de su Línea de Trabajo sobre Planificación Estratégica Regional, la institución del Estado nacional que asiste y acompaña las experiencias en los municipios (y las provincias) interesados ${ }^{7}$. Cabe agregar que la programación, la ejecución y las determinaciones de estos planes son competencia de las jurisdicciones provinciales y municipales.

En la Tabla 1 presentamos la institucionalización de la NOR en la provincia de Formosa.
Acatando los consejos de la NOR, el conjunto de dispositivos y procesos resumido en el cuadro muestra una readecuación de la estructura pública, a fin de asegurar que los intereses privados del mercado estén representados en los procesos de decisión, planeación y ejecución de las políticas "de desarrollo". Esta readecuación, aunque sus elementos constitutivos no sean necesariamente idénticos, configura una nueva regulación neoliberalizadora, entendida esta como la movilización del poder estatal en vistas a extender y reproducir contradictoriamente el dominio del mercado y las consecuencias sociales de este dominio. Tomando las nociones de Tickell y Peck (2003), podemos capturar conceptualmente este proceso a través de la noción de neoliberalismo de reconstrucción (roll-out), de nuevas formas de construcción de instituciones y de intervención gubernamental, diferente al momento "destructivo" (roll-back) de los noventa ${ }^{8}$.

$7 \quad$ EL CFI es un organismo de las provincias argentinas creado en el año 1959, esto es, en plena vigencia del Estado desarrollista, mediante un Pacto Federal. Su misión es promover el desarrollo armónico e integral del país en base a un esquema solidario y descentralizado. Para ello, utiliza dos grandes herramientas: la cooperación técnica y la asistencia financiera. La entidad acompañó el financiamiento de los procesos de Planes Estratégicos de Desarrollo Local en el territorio de Formosa (Consejo Federal de Inversiones [CFI], s.f.)

8 "(...) la práctica del neoliberalismo tiene poco que ver con la desregulación laissez-faire -dejar a los mercados que hagan su trabajo, Estado ausente-, sino que está asociada a la deconstrucción extensiva y la reconstrucción de instituciones frecuentemente en nombre de o en la imagen de los 'mercados'” (Tickell \& Peck, 2003, pp. 167-68). 
Tabla 1. Institucionalización de la NOR en la provincia de Formosa

\begin{tabular}{|c|c|c|}
\hline \multirow{2}{*}{ Instituciones líderes } & Escala mesorregional & Escala microrregional o local \\
\hline & \multicolumn{2}{|c|}{ Estrategia - Programas de Competitividad y Clúster } \\
\hline 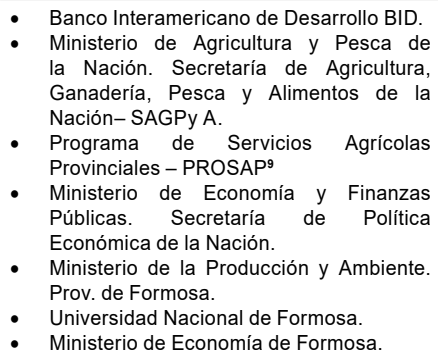 & $\begin{array}{l}\text { - Estrategia Provincial para el Sector } \\
\text { Agroalimentario -EPSA. - Resoluciones } \\
373 / 09 \text { y 3550/15 Ministerio de la Producción } \\
\text { y Ambiente. } \\
\text { - Plan de Mejoramiento de la Competitividad } \\
\text { (PMC) - Clúster Acuícola del NEA y frutícola } \\
\text { NOA con aportes de CEDEVA. } \\
\text { Programa de Competitividad de Norte } \\
\text { Grande (PCNG): Plan de Competitividad del } \\
\text { Conglomerado Bovino de Formosa. } \\
\text { PCNG: Plan de Competitividad del } \\
\text { Conglomerado Productivo Foresto Industrial } \\
\text { de Formosa. } \\
\text { Proyecto de desarrollo del centro-oeste. }\end{array}$ & $\begin{array}{l}\text { El Plan Estratégico Formosa 2015, divide a } \\
\text { la provincia en } 8 \text { regiones productivas en las } \\
\text { que operan las estrategias, programas de } \\
\text { competitividad y clúster: } \\
\text { 1) Litoral. 2) Subtropical Norte. 3) Pirané Sur. } \\
\text { 4) Pirané Norte. 5) Central Norte. 6) Central } \\
\text { Sur. 7) Centro Oeste y 8) Extremo Oeste. } \\
\text { A su vez, se constituyen } 4 \text { macrorregiones } \\
\text { inclusivas de una o parte de las } 8 \text { regiones. } \\
\text { Ellas son: } \\
\text { - Macrorregión Centro-Oeste } \\
\text { - Macrorregión Central. } \\
\text { - Macrorregión Subtropcial Norte. } \\
\text { - Macrorregión Este. }\end{array}$ \\
\hline & Bosque Modelo Formoseño - BMFo & \\
\hline 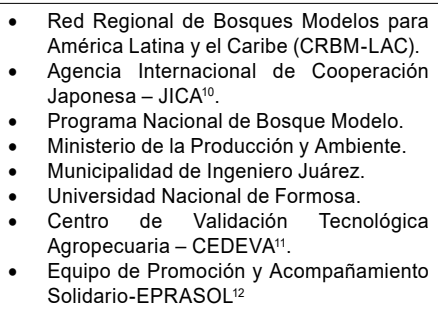 & & $\begin{array}{l}\text { El BMFo opera en la localidad de Ingeniero } \\
\text { Juárez, Provincia de Formosa. Es una } \\
\text { asociación civil sin fines de lucro, creada en } \\
\text { el año 1998. Obtuvo su personería jurídica } \\
\text { en } 2004 \text {. Su área de incidencia: } 800000 \text { ha, } \\
\text { poblada por } 45000 \text { habitantes divididas a su } \\
\text { vez en diferentes formas de convivencia con } \\
\text { su entorno. Son cuatro los centros poblados } \\
\text { con más de } 1000 \text { habitantes, donde viven } \\
\text { criollos y aborígenes (qom y wichí). (Anuario } \\
\text { B M, 2010) }\end{array}$ \\
\hline
\end{tabular}

Plan Estratégico Territorial y

Planes Estratégicos de Desarrollo Local

Planes Estratégicos de Desarrollo

BID

PNUD Argentina.

Ministerio de Planificación Inversión Obras y

Servicios Públicos de la Nación.

Consejo Federal de Inversiones -CFI

Fundación Arandú-Provincia de Corrientes.

Ministerio de Planificación Inversión Obras y

Servicios Públicos de la Formosa.

Dirección de Planificación del Desarrollo Local

de Formosa.

Municipios seleccionados.
Local PEDL en municipios

seleccionados por la provincia:

1. Herradura

2. Misión Lahisí

3. Riacho $\mathrm{He} \mathrm{He}$

4. Laguna Blanca

5. Clorinda

6. Tres Lagunas

7. General Belgrano

8. Villafañe

9. Pirané

10. Palo Santo

11. San Martín II

12. Siete Palmas

13. El Espinillo

14. Fortín Lugones

15. El Colorado

$9 \quad$ La entidad financia proyectos a través de la inversión pública directa, la inversión pública articulada con el sector privado e iniciativas de mejora competitiva. A través de este abanico de inversiones, se formulan, financian y ejecutan proyectos que promueven superar las barreras que limitan el crecimiento y la competitividad de actividades agropecuarias. Entre sus instrumentos de implicación se hallan las Iniciativas de Desarrollo de Clúster IDC (PROSAP, s.f.)

10 Constituida como Institución Administrativa Independiente, la Agencia de Cooperación Internacional del Japón JICA tiene como fin contribuir a la promoción de la cooperación internacional, así como, al firme desarrollo de las economías de Japón y de todo el mundo, dando apoyo al desarrollo socioeconómico, la recuperación o la estabilidad económica de los países en desarrollo (JICA, s.f.)I

11 La misión del CEDEVA es producir información disponible para los empresarios que vengan a invertir a las regiones productivas y a la vez generar todo un paquete de tecnología que se adapte a la región oeste y centro-oeste donde la agricultura no existía (Formosa, s.f.)

12 Es una asociación civil sin fines de lucro, que se dedica a la promoción humana integral de comunidades aborígenes del oeste de Formosa. 


\section{Continuación Tabla 1}

\begin{tabular}{|c|c|}
\hline & $\begin{array}{l}\text { 16. Villa Dos Trece } \\
\text { 17. General Güemes } \\
\text { 18. Ibarreta } \\
\text { 19. Estanislao del Campo } \\
\text { 20. Ingeniero Juárez } \\
\text { 21. General Enrique Mosconi } \\
\text { 22. Pozo de Maza } \\
\text { 23. Laguna Naineck } \\
\text { 24. Buena Vista } \\
\text { 25. Región Centro - Este. }\end{array}$ \\
\hline & $\begin{array}{l}\text { Referencias teóricas de los planes: basadas en documentos y manuales } \\
\text { de CEPAL-ILPES y Cadena de Valor de base Porteriana. }\end{array}$ \\
\hline $\begin{array}{l}\text { Agencia de Desarrollo Empresarial } \\
\text { - } \mathrm{ADE}^{13} \text { FORMOSA. }\end{array}$ & $\begin{array}{l}\text { - } \quad \text { Feria Internacional de Mueble y la Madera -FEDEMA- Formosa } \\
\text { - } \quad \text { Feria Internacional de Frutos Argentinos -FRUTAR- Formosa. } \\
\text { - } \quad \text { Programa de Entrenamiento Gerencial Para Empresas Industriales. } \\
\text { - } \quad \text { Programa de Visita y Apoyo a Empresas. } \\
\text { - Programa de Acceso al Crédito y la Competitividad. } \\
\quad \text { Pequeña y Mediana Empresa -FONAPYME-. } \\
\text { - Programa Capital Semilla }\end{array}$ \\
\hline
\end{tabular}

Fuente: elaboración propia con base en fuentes documentales de organismos oficiales de la provincia de Formosa.

Vinculado a este momento que viene a "complementar" la etapa previa de regulación neoliberalizadora, gana influencia también el enfoque de las cadenas globales de valor (CGV). El marco de las CGV, muy influyente en el estudio de los procesos económicos contemporáneos, se ha convertido en el presente siglo -y en el marco del Posconsenso de Washington-, en una referencia para la formulación de políticas de desarrollo, siendo adoptado por los organismos supranacionales y las instituciones financieras (Fernández \& Trevignani, 2015; McMichael, 2013). En términos de posibilidades de desarrollo, la idea medular que se promueve consiste en que la integración por parte de las unidades productivas de los países periféricos a estas cadenas globales es una condición indispensable para iniciar o afianzar senderos de desarrollo económico. Concomitantemente, se considera que es posible establecer conexiones cooperativas y de no suma cero entre actores tan disímiles como las firmas transnacionales, que son las que controlan las redes globales, y las pequeñas unidades productivas que operan en regiones deprimidas de los países periféricos, y a eso debe estar orientada la implicación estatal.

\section{ANÁLISIS DE LAS INTERVENCIO- NES ESTATALES EN EL COMPLE- JO ALGODONERO FORMOSEÑO}

A partir de la campaña 2002-2003, diversos factores concurrentes, de orden internacional y doméstico, propiciaron la recuperación de la agricultura del algodón en la nación y, dentro de ella,

13 La ADE es una institución sin fines de lucro donde confluyen los esfuerzos de empresarios, cámaras, universitarios, técnicos y organismos gubernamentales para desarrollar las potencialidades de la economía regional y mejorar la competitividad de las empresas. (ADE Formosa, s.f.) 
la formoseña. ${ }^{14}$ En dicho escenario, el Estado provincial, en el marco de las políticas de aliento a los agronegocios llevada adelante por el Estado nacional, y en sintonía con la NOR, implementa una política de fomento de la agricultura intensiva en la producción algodonera mediante la difusión entre los agricultores locales del "paquete tecnológico" de la "segunda revolución verde", basado en la biotecnología ${ }^{15}$. Lo peculiar del caso formoseño -dentro un cuadro general común a toda la Argentina- es el carácter manifiestamente activista de la intervención de las agencias gubernamentales en pro de la biotecnología, al punto de configurar "todo un esquema de producción regenteado por el Estado, que incluye hasta la prestación de servicio de la maquinaria específica" (Arza \& Van Zwanenberg, 2015, p. 217).

El bloque tecnológico comienza a ser impulsado activamente en 2005 y se estructura en torno a las variedades transgénicas del algodón, a las que van unidas la adopción de prácticas de siembra en surcos estrechos, la intensificación en el uso de biocidas (especialmente herbicidas), la adopción de maquinaria moderna para la recolección y el uso de prácticas de manejo apropiadas. El discurso gubernamental promueve la adopción de esta tecnología siguiendo el argumento estándar de los defensores de los transgénicos a escala internacional, esto es, presentándola como la única vía para solucionar los problemas económicos y ambientales que aquejan a la agricultura de los países subdesarrollados aumentando la productividad y reduciendo la dependencia de agroquímicos (Glover, 2010). De esta manera, se dice, impediría también la desaparición de los pequeños productores.

La producción algodonera provincial está en manos de dos tipos de sujetos económicos: una estrecha franja de productores familiares capitalizados y una amplia base de productores familiares minifundistas. El Estado los atiende de manera diferenciada. A los primeros se les vende la semilla y los insumos asociados, brindándoles además asistencia financiera a través de créditos otorgados por el mismo Estado. A los últimos se les entrega el paquete tecnológico sin costo económico alguno, como parte de los servicios brindados

14 Entre 1930 y 1980 , el monocultivo del algodón fue la actividad económica medular de la provincia de Formosa. Laboreado en pequeñas fincas familiares, mayoritariamente minifundistas, el algodón en bruto se desmotaba seguidamente en la provincia, para después ser trasladado, por los trusts que controlaban el eslabón comercial, a las hilanderías y tejedurías ubicadas en otros distritos provinciales. Afectada por crisis de sobreproducción ya desde 1960, la labranza algodonera provincial arrastró, con algunos altibajos, un estancamiento crónico de décadas, hasta que, en los primeros años de la década del noventa, como efecto del brutal plan de ajuste neoliberal, sufrió un colapso casi terminal. Después de una leve recuperación, en la segunda mitad de esa década, se desploma nuevamente a comienzos del siglo XXI. En la campaña 2001-02, con 8000 hectáreas sembradas, el algodón, y con él gran parte de la agricultura familiar, íntimamente atada a su cultivo, casi desaparece del paisaje provincial (Sapkus, 2014)

15 Bloque tecnológico conformado por la tríada "semilla transgénica-agroquímicos-siembra directa”, que comenzó a difundirse en la agricultura argentina en la segunda mitad de los noventa y que alcanzó con fuerza al algodón ya en el presente siglo. 
por el Instituto Provincial de Acción Integral para el Pequeño Productor Agropecuario (IPAIPPA) ${ }^{16}$.

El IPAIPPA también asiste al sector minifundista con la maquinaria específica para la siembra, las labores culturales y la recolección de los capullos maduros, además de brindarle el asesoramiento técnico para la adaptación del modelo sociotécnico centrado en la semilla transgénica a la realidad de las fincas pequeñas (esto último en colaboración con el Instituto Nacional de Tecnología Agropecuaria-INTA-). Al final de la zafra algodonera, se les descuenta el costo de este laboreo mecánico al momento de comprar la cosecha, en los centros acopiadores instalados por el mismo Estado. De este modo, el Estado provincial es el actor decisivo y necesario para llevar adelante el cultivo del algodón transgénico en la provincia de Formosa.

El Estado provincial formoseño, entonces, ha desarrollado un dispositivo original de transferencia de tecnología y organización de la producción entre los sectores más vulnerables de la cadena algodonera en función de los requisitos de las empresas agrícolas transnacionales; y particularmente de una de ellas: Monsanto, cuyo rol como suministrador de insumos críticos ("proveedor de tecnología") para la agricultura argentina creció notablemente desde los noventa y se consolidó en la etapa posconvertibili$\mathrm{dad}^{17}$. Tal dispositivo intenta aumentar la productividad de la agricultura familiar provincial, al inducir que la misma asuma funciones tecnológicamente más avanzadas (o que pretenden serlo), y profundizar las relaciones mercantiles en el campo, atando de modo extremadamente subordinado la economía rural provincial a una dinámica transnacionalizada de rumbo impredecible y de consecuencias sociales y ambientales poco claras. En conclusión, mediante arreglos escalares verticalizantes que se imponen principalmente en el territorio de la mano del IPAIPPA, la política pública provincial se adapta activamente a los requerimientos locales de las fracciones transnacionales que controlan las cadenas globales de valor.

16 El IPAIPPA es un organismo clave en la gobernanza y control político y social institucionalizado de los pobres rurales de la provincia. Tuvo su origen en 1996 como Programa de Asistencia Integral al Pequeño Productor Agropecuario (PAIPPA), con el objetivo declarado de: "crear un marco solidario de los productores rurales más humildes, tendiente a lograr su autosostenimiento, incrementar el nivel de ocupación y propender a la autogestión (...)" (Informe sobre Desarrollo Humano 1999 de la provincia de Formosa, p. 14). En términos concretos, el PAIPPA era una intervención de política social trabajista y focalizada diseñada como paliativo de los efectos más devastadores del alto neoliberalismo en la provincia, que tiene continuidad en el tiempo, sin grandes modificaciones en la naturaleza de la asistencia a la "población objeto", al perpetuarse las condiciones de extrema pobreza del segmento más sumergido de las capas rurales subalternas. En 2004 el PAIPPA se transforma en IPAIPPA (Decreto 641/04 del PEP). EI IPAIPPA continúa la línea de intervención del PAIPPA, intentando ahora convertirse en "una gigantesca empresa solidaria capaz de producir y comercializar en escalas más ambiciosas" (IPAIPPA, 2004).

17 En el período que comprende nuestra investigación, Monsanto monopolizaba la propiedad de las semillas transgénicas de algodón disponibles en Argentina. Además, era la principal empresa proveedora del herbicida más utilizado en la agricultura argentina: el glifosato. En 2008 la firma transnacional firmó un "Acuerdo marco para el desarrollo sustentable del cultivo el algodón" con el gobierno de Formosa y de otras provincias algodonera por el cual se aseguraba el reconocimiento de la "propiedad intelectual" de las semillas transgénicas, pasando a tener, con este monopolio, una influencia preeminente en el sector algodonero argentino. 
Por lo pronto, los resultados a corto plazo, en términos de producción $\mathrm{y}$ productividad por unidad de superficie, son claramente desalentadores, como podemos ver en el Tabla 2.

Tabla 2. Algodón: producción de Formosa y del país, superficie sembrada en Formosa y participación de la producción provincial en el total del país (campañas 2002/03-2014/15)

\begin{tabular}{ccccc}
\hline Campañas & $\begin{array}{c}\text { Provincia de Formosa } \\
\text { (en toneladas) }\end{array}$ & $\begin{array}{c}\text { Superficie sembrada } \\
\text { (en hectáreas) }\end{array}$ & $\begin{array}{c}\text { Total del país } \\
\text { (en toneladas) }\end{array}$ & $\begin{array}{c}\text { Participación } \\
\text { de la provincia } \\
\text { en el total del } \\
\text { país (en \%) }\end{array}$ \\
\hline $2002 / 2003$ & 23.867 & 17.000 & 201.510 & 12 \\
\hline $2003 / 2004$ & 44.544 & 33.279 & 354.000 & 13 \\
\hline $2004 / 2005$ & 46.888 & 51.700 & 448.000 & 10 \\
\hline $2005 / 2006$ & 35.100 & 27.000 & 315.000 & 11 \\
\hline $2006 / 2007$ & 38.000 & 35.000 & 545.400 & 7 \\
\hline $2007 / 2008$ & 19.690 & 17.440 & 493.600 & 2 \\
\hline $2008 / 2009$ & 18.480 & 15.400 & 389.000 & 2 \\
\hline $2009 / 2010$ & 12.150 & 18.030 & 735.500 & 4 \\
\hline $2010 / 2011$ & 24.000 & 20.000 & 1.155 .800 & 4 \\
\hline $2011 / 2012$ & 30.600 & 26.500 & 708.870 & 2 \\
\hline $2012 / 2013$ & 22.980 & 19.000 & 543.008 & 2 \\
\hline $2013 / 2014$ & 11.760 & 12.500 & 1.019 .654 & 2 \\
\hline $2014 / 2015$ & 18.000 & 18.000 & 795.345 & \\
\hline
\end{tabular}

Fuente: elaboración propia con base en datos del Ministerio de Agricultura, Ganadería y Pesca de la Nación

Poco tiempo después de comenzar a fomentar de este modo la producción primaria algodonera, el Estado Provincial diseñó una intervención en el eslabón manufacturero de la cadena textil a través del Programa de Desarrollo Productivo Industrial del Sector Textil-Fondo Textil Formosa (FONTEX). Lanzado en 2010, el Programa fue pergeñado para promover microemprendimientos productivos textiles ${ }^{18}$. Más específicamente, se plantea generar agrupamientos asociativos de individuos para desempeñar tareas de confec- ción de indumentaria. Generados desde el mismo Estado, a esto grupos se los asiste con herramientas, insumos, bienes de capital, créditos y, en vinculación con otras agencias del Estado nacional, capacitación. El producto es adquirido, por lo menos en una primera fase, por el mismo Estado Provincial -para ser utilizado en organismos públicos- ${ }^{19}$.

El Programa comenzó a implementarse en 2011. En 2014, según las fuentes oficiales, ya se había constituido una red de 38 grupos asociativos -aglutinando

18 Decreto 693 de 2010.

19 Originalmente, el Programa pretendía que los grupos cooperativos pudieran, con el tiempo, "captar el mercado privado". Pero, en el período que abarca la presente investigación, hasta 2015, prácticamente la totalidad de lo producido lo adquiría el estado provincial. 
a 400 personas- distribuidos en toda la provincia. Los costureros asociados ${ }^{20}$, que operaban 180 máquinas de distinto tipo en 60 talleres, llevaban confeccionados, hasta comienzos de ese mismo año, 120000 delantales para las escuelas provinciales $^{21}$. Además, producían decenas de sábanas que eran distribuidas en los hospitales públicos, vendiéndose un escaso número a un importante hotel de la ciudad capital.

Para los funcionarios responsables del área, estos datos indicaban que el Proyecto se había convertido en un éxito empresarial en el que vislumbraban un avance en el tejido industrial de la provincia. Desde un ángulo algo distinto, y esgrimiendo un discurso más decididamente "flexibilizador", también se resalta la generación de toda una dinámica "emprendedorista" en la economía local. En esa línea, uno de los funcionarios comenta: "muchas mujeres, que hasta no hace mucho eran humildes modistas, han pasado a convertirse en empresarias textiles, de baja escala, pero con un futuro muy promisorio" (Formosa, 2012). Desde el Estado provincial, así, se resalta al programa desde un discurso del "empoderamiento" que provocaría esta intervención estatal, provocando una dinámica virtuosa de crecimiento económico, avance "industrial" e "inclusión social".

En términos más concretos, el Programa Fontex consiste en la aplicación a escala provincial, y en términos de organización asociativa, del proceso productivo y de la gestión del emprendimiento, del modelo de las unidades productivas tipo (UPT), un Subprograma del Instituto Nacional de Tecnología Industrial (INTI $)^{22}$. El Subprograma, en vinculación con diferentes instancias estatales y con algunas ONG, brinda asesoramiento técnico "integral" (producción, gestión y comercialización) a las personas ocupadas en grupos asociativos que actúan en el sector informal de la economía ${ }^{23}$. En otras palabras, es un programa diseñado para dar respuesta laboral de emergencia a los trabajadores inactivos o con una vinculación intermitente con el mercado de trabajo.

En Formosa, cerca del $90 \%$ de las personas ocupadas en el Programa desempeña tareas de confección, y casi todas

20 Cada unidad productiva toma la forma de consorcio de cooperación o cooperativa de trabajo y está compuesta por 5 talleres de 3 personas cada uno y 4 personas abocadas a los servicios comunes de terminación de la prenda.

21 El Estado compra las telas a empresas hilanderas; las corta en el taller sede del Programa ubicado en la ciudad capital y las distribuye a las cooperativas dispersas en toda la provincia para su costura.

22 El INTI es un ente autárquico que funciona bajo la órbita del Ministerio de Producción y Trabajo de la Nación, y tiene como misión "fortalecer la competitividad industrial en todo el país a través de la transferencia de tecnología (...) y el impulso al desarrollo tecnológico, y la innovación en todos los sectores productivos", según reza en su página web (inti.gob.ar/conoces-al-inti). Fue creado en 1957, como parte del conjunto de instituciones creadas por entonces en el marco de la política desarrollista de impulso estatal a la ciencia y la tecnología. (INTI, s.f.)

23 El Subprograma de las UPT formaba parte de un esquema mayor dentro del INTI: el Programa Extensión. Criado y Vázquez explican que: "(...) el Programa Extensión es un producto del cambio institucional que se produce en el INTI, a partir del año 2002. Ese Instituto hasta ese entonces estaba organizado a partir de los centros especializados por actividades de la economía que brindan asistencia técnica a empresas. Desde ese año a la lógica de intervención de los centros se suma el Programa Extensión que incorpora la "tecnología de apropiación colectiva" como uno de los ejes de intervención en la nueva etapa" (Criado \& Vázquez, 2007, p. 17). 
ellas son mujeres. Estas costureras laboran en pequeñas unidades productivas, encuadradas nominalmente como "cooperativas de trabajo", ejecutando tareas de escasa calificación -la concepción y el diseño de las prendas-, mientras que la administración y supervisión de producto están a cargo de otros eslabones de la jerarquía organizativa de Estado. La figura jurídica de "socia cooperaria" ubica a estas obreras fuera del derecho del trabajo y la seguridad social, y su actividad económica se encuentra regulada por el derecho civil o comercial. En este sentido, el Estado las contrata como "trabajadoras autónomas", bajo el régimen del monotributo. Una jornalera comenta en una entrevista:

'Trabajamos mañana y tarde algunas de las personas que trabajan aquí llevan trabajo a sus casas', explicó una de las costureras consultadas mientras aclaraba que trabajaba para la cooperativa dentro del programa Fontex (...) 'Cobro por monotributo, me hice monotributista hace un mes aproximadamente y nos pagan con un recibo que no es un sueldo pero aún no tengo aporte jubilatorio' (...) 'Nosotras ganamos según las prendas que producimos, cada una cobra su producción y trabajamos entre grupos de tres y se hacen guardapolvos en secuencias, el corte ya viene hecho desde Fontex, confeccionamos todo lo que sea costura recta y terminaciones de ojales, botones y empaquetado'. A su vez, dio a conocer: 'que lo que sea de costura recta nos están pagando $\$ 19$ y terminado $\$ 22$ '. (El Comercial, 2012)

Como se desprende de la cita, las condiciones de trabajo no solo son heterónomas, como veníamos señalando, sino que claramente corresponden a empleos precarios del segmento secundario de trabajo ${ }^{24}$. Trabajar como costurera del Fontex supone un empleo precario sin garantía de estabilidad, con prolongadas jornadas laborales en condiciones endebles, vulnerables e inciertas en cuanto a la permanencia en la actividad y la percepción de ingresos, con escasa protección legal y social.

Las palabras de un funcionario provincial completan el cuadro descriptivo:

'(...) Cuando el gobierno de la Provincia de Formosa, más precisamente a pedido del Gobernador, se mete en esto del sector textil, pide que mano de obra formoseña confeccione guardapolvos, a partir de allí se inicia la búsqueda de costureras (..)'. '(...). Fontex ha permitido la inclusión laboral de 450 personas. Cuatrocientas asociadas a las cooperativas y consorcios trabajando directamente sobre las máquinas y 50 ocupándose de la parte operativa, la logística y la capacitación (...).’ '(...) Se producen 140 mil guardapolvos que son entregados gratuitamente. Esto le ha permitido al Estado un ahorro, ya que antes debía erogar el monto total

24 Los empleos en el segmento primario son "de alta calidad por contar con estabilidad, ingresos por sobre los mínimos de subsistencia, aportes a la seguridad social y protección legal”. Los del segmento secundario, en cambio, "son empleos sin protección legal ni social, trabajos con ingreso por debajo de las necesidades de subsistencia, o incluso, subocupaciones que se desarrollan en el marco de los programas de empleo público" (Salvia et al., 2006, p. 4). 
de adquisición de los guardapolvos, y hoy los paga mes a mes, ¿Por qué?, porque las confeccionistas y todas las cooperativas y consorcios van cobrando a medida que van confeccionando los guardapolvos y así se genera un desahogo para arcas de la Provincia de Formosa (Emprender en la Región, 2013) (...)'. '(...) El programa Fontex no paga un sueldo, sino que reciben un ingreso por sus costuras que vienen realizando, hablamos de algunas costureras de unos 4000 pesos por mes'. (FTC Noticias, 2014)

En la cita se reconoce explícitamente que la modalidad precarizada y flexibilizada de trabajo en la que laboran las costureras le permite el ahorro de costos al Estado. Asimismo, señala que solo algunas de ellas pueden alcanzar una remuneración de 4000 pesos mensuales, el nivel de la canasta familiar de pobreza en Formosa en ese año. En tal sentido, los agrupamientos asociativos de costureras de FONTEX funcionan más como una estrategia de tercerización o subcontratación por parte del Estado, que como un factor dinamizador de la economía y generador de empleo estable y de calidad y promotor de la superación de la pobreza en la provincia. Los agrupamientos asociativos de costureras de Fontex configuran, por ende, "seudocooperativas de trabajo", compuestos por asalariadas que trabajan a destajo disfrazadas de socias cooperarias ${ }^{25}$.

En definitiva, y sintetizando lo presentado hasta aquí, el Estado provincial actúa en esta etapa en el sector algodonero y textil con una regulación escalar fragmentante y neoliberalizadora. Por una parte, buscando integrar de manera peculiar a los pequeños campesinos a las "cadenas agrícolas de valor" (McMichael, 2013), convirtiéndolos compulsivamente en consumidores de paquetes tecnológicos de última generación en beneficio de los detentadores del capital más concentrado del agronegocio (agribusiness) mundial. Pero, más allá de las implicaciones sociales y ambientales más generales de este proceso de industrialización de la agricultura familiar formoseña, $y$ ateniéndonos a los propios parámetros del paradigma productivista que impulsa el Gobierno, los resultados de esta política son magros. En efecto, el objetivo básico y legitimador de toda la innovación tecnológica, el incremento de los rendimientos, no se ha logrado (como se muestra en la Tabla 1). Tampoco se ha avanzado en los eslabonamientos endógenos hacia atrás y hacia adelante que se pregonaban, y que podrían indicar algún tipo de densificación de la trama productiva territorial $^{26}$. Por otra parte, y

25 Tomamos la expresión "seudocooperativas" de Neffa (2008, pp. 98-99). Cabe agregar que esta modalidad permite al empleador, en este caso el Estado provincial, reducir costos laborales (salarios directos e indirectos), como así también restringir la planta de personal estable a fin de facilitar la gestión de la fuerza de trabajo y reducir la representación sindical

26 Originalmente, se tenía prevista la instalación de una fábrica de cosechadoras de algodón adaptadas al surco estrecho en la ciudad de Formosa. Además, también se había planificado la recuperación de una antigua hilandería que había funcionado en la misma ciudad hasta la década de 1980. Ninguno de los dos proyectos se concretó. 
sin conexión con el proceso agrícola antes comentado, se ha montado el programa textil FONTEX, una intervención de carácter trabajista, esto es, una política social "activa" para el segmento femenino de las capas sociales vulnerables, sin relación alguna con algún tipo de estrategia industrial.

\section{CONCLUSIONES}

Este análisis pretende dar cuenta de un caso de puesta en marcha de políticas públicas de carácter neoliberalizador y trabajista, desplegadas en el marco de un patrón regulativo reescalado, en una jurisdicción subnacional argentina notoriamente rezagada y con escaso dinamismo económico. Esta intervención estatal se produce durante un período en el que el Gobierno argentino abandonó el neoliberalismo extremo de los noventa y comenzó un camino de recuperación de ciertas capacidades institucionales del Estado central, pasando a ser este un actor económico relevante e incluso un agente de redistribución.

Hemos abordado el asunto en dos acápites. En el primero presentamos los postulados generales de la NOR y su arribo a la provincia de Formosa. Teniendo en cuenta este encuadre general, en el segundo hicimos un acercamiento empírico a una intervención sectorial-territorial, guiada por las nociones de la NOR, en la rama textil de la provincia de Formosa.
La NOR se configuró como una ortodoxia para las políticas regionales a partir de la teorización basada en algunos casos de particular dinamismo económico en territorios localizados de los países centrales. En la década del noventa se transforma en la manera indiscutible de abordar las economías locales y regionales en todo el mundo, como parte del momento culminante del neoliberalismo global. El giro hacia formas más complejas, creativas y reconstructivas de neoliberalización en países como Argentina a comienzos de este siglo, con un renovado protagonismo del Estado central y una retórica antineoliberal, no implicó dejar de lado los lineamientos centrales del nuevo regionalismo.

En efecto, las políticas públicas sobre la cuestión de las disparidades regionales en Argentina implementadas a partir de 2003 reformulan la NOR, sin abandonarla. Si bien la ideología neoliberal ortodoxa se pone cada vez más en entredicho, la maquinaria política de imposición de la disciplina de mercado por vías estatales se mantiene esencialmente intacta. Las agendas políticas y sociales siguen estando subordinadas a la prioridad de mantener un buen clima de negocios y la confianza de los inversores, con mercados de trabajo flexibilizados, y enfocadas cada vez más a la inserción en las cadenas globales de valor. El dispositivo de organismos y planes impuestos en la provincia de Formosa, descritos en la sección 2, ilustran esta senda. 
Posteriormente, analizamos la doble intervención estatal provincial en el Complejo Algodonero Formoseño durante el mismo período. En este caso observamos que, en el marco de los avances del Estado central implicado en programas como los PET y los PEDL, el Estado provincial actúa sobre la débil capa de pequeños productores algodoneros para, esencialmente, incorporarlas compulsivamente y de modo subordinado a la lógica del modelo de los agronegocios. Por otro lado, y ante la ausencia de un encadenamiento productivo territorialmente anclado, el Estado provincial asiste a las capas vulnerables de la población incorporándolas a un esquema trabajista de subcontratación disfrazado de cooperativas de trabajo para la confección final de prendas de vestir. En ambos casos, el discurso y el esquema del desarrollo local/regional actúa controlando a la población rural/ urbana marginalizada y precarizada de la provincia.
En definitiva, en el contexto del viraje "posneoliberal" general del Estado argentino, el Estado provincial interviene sobre la economía de una manera decididamente neoliberalizadora, intenta crear ambientes productivos "competitivos" y "flexibilizados" que aseguren la rentabilidad del capital a bajo costo, vinculados a la producción y elaboración de la fibra textil en espacios rurales y urbanos degradados y precarios. Se acentúa de tal modo la heterogeneidad estructural de la ya débil economía provincial, profundizando por añadidura el deterioro de las ya míseras condiciones de vida de la población trabajadora.

\section{DECLARACIÓN DE CONFLCITO DE INTERES}

Los autores declaran que no existe conflicto de intereses. 


\section{REFERENCIAS}

ADE Formosa. (s.f.). Agencia de Desarrollo Empresarial ADE. www.adeformosa. org.ar

Adriani, H. L. (2016). Territorio y desarrollo en la Argentina posconvertibilidad. En M. Féliz, E. López \& M. García (coords.) Desarmando el modelo. Desarrollo, conflicto y cambio social tras una década de neodesarrollismo (pp. 261-76). El Colectivo.

Amin, A. \& K. Robins (1990). The Re-emergence of Regional Economies? The Mythical Geography of Flexible Accumulation. Society and Space, 8, 7-34. https://oi.org/10.1068/d080007

Argentina. (s.f.). Planificación. http://www.planificacion.gob.ar/contenidos/2605

Arza, V. \& Van Zwanenberg, P. (2015). Obstáculos para la coexistencia de modelos alternativos de agricultura: el caso del algodón en Argentina. Desarrollo Económico, 64(2), 411-37.

Cao, H. \& Vaca, J. (2006). Desarrollo regional en la Argentina: la centenaria vigencia de un patrón de asimetría regional. Revista Latinoamericana de Estudios Urbanos y Regionales, 32(95), 95-111. http://dx.doi.org//10.4067/ S0250-71612006000100006

Cetrángolo, O. \& Gatto, F. (2002). Dinámica productiva provincial a fines de los años Noventa. Serie Estudios y Perspectivas 14. Cepal.

Consejo Federal de Inversiones -CFI-. (s.f.). Planificación estratégica regional. http://cfi.org.ar/accionar/lineas-de-trabajo/planificacion-estrategica-regional

Criado, R. \& Vázquez, N. (2007). Calidad del empleo y formas de inserción laboral en las pequeñas unidades industriales. En $8 .{ }^{\circ}$ Congreso Nacional de Estudios del Trabajo. Buenos Aires.

El Comercial. (2012, 8 de mayo). Fontex: Cooperativas cobran sin aporte jubilatorios. Diario El Comercial. http://www.elcomercial.com.ar/index.php?option=com_content\&view=article\&id=76828:fontex--cooperativas-cobran-sin-aporte-jubilatorio\&catid $=54 \&$ Itemid $=55$ 
Emprender en la Región TV. (2013, 13 sept.). Programa de Desarrollo Textil Fontex. [Video]. https://www.youtube.com/watch?v=hyqNWQhLec4

Féliz, M. (2019). El tiempo que nos tocó. Dependencia, crisis y luchas sociales en la Argentina reciente. El Colectivo.

Fernández, V. R. (2016). Desde el laboratorio neodesarrollista a la resurgencianeoliberal. Una revisión creativa del 'doble movimiento' polanyiano en América Latina. Revista Estado y Políticas Públicas, (7), 21-47.

Fernández, V. R. \& Cardozo, L. G. (2012). Nueva estatidad bajo la emergencia regional. La reelaboración del proyecto neoliberal y sus alteraciones en la periferia. Revista Brasileira de Estudios Urbanos e Regionais, 14(2), 11-33. https://doi. org/10.22296/2317-1529.2012v14n2p11

Fernández, V. R. \& Trevignani, M. F. (2015). Cadenas globales de valor y desarrollo: perspectivas críticas desde el Sur Global. Revista de Ciencias Sociais, 58(2), 499-536. https://doi.org/10.1590/00115258201551

Fernández, V. R. \& Comba, D. A. (2017). Sistemas regionales de innovación en la periferia: una perspectiva crítica. Redes, 22(1), 376-401. http://dx.doi. org/10.17058/redes.v22i1.8429

Formosa. (2012). El segmento textil es uno de los que refleja el sostenido crecimiento de la economía local. https://www.formosa.gob.ar/noticia/13880/52/ el_segmento_textil_es_uno_de_los_que_refleja_el_sostenido_crecimiento_de_la_economia_local

Formosa. (s.f.). Cedeva. https://www.formosa.gob.ar/cedeva

FTC Noticias. (2014, 23 ene.). Formosa Fontex. [Video]. https://www.youtube.com/ watch? $=-$ Ep45QGP0Cc

García, A. (2016). Auge y caída de la planificación regional en Argentina: entre la búsqueda de una autonomía enraizada y el escenario económico del capitalismo periférico. Cuadernos de Geografía: Revista Colombiana de Geografía, 27(1), 180-94. http://dx.doi.org/10.15446/rcdg.v27n1.58053.

Giuliano, E. F. (2015). Sociedades periféricas y multiterritorios. Análisis de la estructura social de Formosa en el ciclo 1980-2002. La Colmena. 
Glover, D. (2010). The Corporate Shaping of GM Crops as a Technology for the Poor. Journal of Peasant Studies, 37(1), 67-90. https://doi. org $/ 10.1080 / 03066150903498754$

Hadjimichalis, C. (2011). SMEs, Entrepeneurialism, and Local/Regional Development. In Pike, A. Rodríguez-Posse \& J. Tomaney (eds.) Handbook of Local and Regional Development (pp. 381-93). Routledge.

Harvey, D. (2004). El nuevo imperialismo. Akal.

Ipaippa. (2004). Programa de Asistencia Integral al Pequeño Productor Agropecuario. Ipaippa.

INTI. (s.f.). ¿Conocés al Inti? inti.gob.ar/conoces-al-inti

Jessop, R. (2008). El futuro del Estado capitalista. De la Catarata.

JICA. (s.f.). Agencia de Cooperación Internacional del Japón. http://www.jica.go.jp/ spanish/index.html

Katz, C. (2013). Manifestaciones de la crisis en América Latina y las paradojas del neodesarrollismo argentino. Caderno CRH, 26(67), 49-64 http://dx.doi. org/10.1590/S0103-49792013000100004

Madoery, O. (2011). Política y territorio en Argentina. Desenvolvimento regional em debate, 1(1), 24-39. https://doi.org/10.24302/drd.vli1.63

Manzanal, M. (2000). Neoliberalismo y territorio en la Argentina de fin de siglo. Economía, Sociedad y Territorio, 2(7), 433-58. https://doi.org/10.22136/ est002000438

McMichael, P. (2013). Value Chain Agriculture and Debt Relations: Contradictory Outcomes. Third World Quarterly, 34(4), 671-90. https://doi.org/10.1080/01436 597.2013 .786290

Neffa, J. C. (2008). Empleo informal, trabajo no registrado y trabajo precario. Dimensiones teóricas y conceptuales. En J. C. Neffa (coord.) La informalidad, la precarización laboral y el empleo no registrado en la provincia de Buenos Aires (pp. 15-139). Ministerio de Trabajo de la Provincia de Buenos Aires/ CEIL. 
Panigo, D. \& Chena, P. (2011). Del neo-mercantilismo al tipo de cambio múltiple para el desarrollo. Los dos modelos de la posconvertibilidad. En Ensayos en honor a Marcelo Diamand (pp. 241-66). Miño y Dávila.

Pinassi, M. O. \& Adoue, S. B. (2019). Primer prólogo. En M. Féliz, El tiempo que nos tocó. Dependencia, crisis y luchas sociales en la Argentina reciente (pp. 11-17). El Colectivo.

PROSAP. (s.f.). Programa de servicios agricolas provinciales. http://www.prosap. gov.ar

Salvia, S. (2019). El modo de acumulación en la Argentina reciente. Del neoliberalismo a la posconvertibilidad. En A. Bonnet \& A. Piva (comps.) El modo de acumulación en la Argentina contemporánea (pp. 51-70). Imago Mundi.

Salvia, A., Fraguglia, L. \& Metlika, U. (2006). ¿Disipación del desempleo o espejismo de la Argentina postdevaluación? Lavboratorio, 8(19).

Salvia, A. \& Gutiérrez-Ageitos, P. (2013). La estructura social del trabajo en Argentina en el cambio de siglo: cuando lo nuevo no termina de nacer. Papeles de Trabajo, 19(76), 163-200.

Sapkus, S. (2014). Cambo agrario y reconfiguración de las relaciones sociales en Formosa. Publicar en Ciencias Sociales, 13(16), 103-20.

Tickell, A. \& Peck, J. (2003). Making Global Rules. Globalization or Neoliberalization? In J. Peck \& H. W. Young (eds.) Making the Global Economy (pp. 163-1). https:// doi.org/10.4135/9781446216767.n10 